\title{
TIME OF LEAFROLLER INFESTATION AND EFFECT ON YIELD IN GRAPES
}

\author{
P.L. LO and V.C. MURRELL \\ HortResearch, Hawke's Bay Research Centre, Private Bag 1401, \\ Havelock North, New Zealand
}

\begin{abstract}
Leafroller (Lepidoptera: Tortricidae) larvae damage grape bunches directly by feeding on the flowers, berries and stalks. Damaged berries can become infected by fungi such as Botrytis cinerea that cause diseases, leading to further indirect yield losses. In a field trial, Chardonnay bunches were infested with lightbrown apple moth, Epiphyas postvittana, larvae at monthly intervals from December to March. The greatest losses (12\% of the fresh weight at harvest) occurred in bunches infested in December and March. In December, the main cause of loss of berries was direct feeding damage, whereas by March, indirect losses to disease outweighed those directly due to larvae. Leafroller infestations up to January did not increase disease in bunches above the background level of infection. In Hawke's Bay, leafrollers have the greatest effect on yields from February onwards when infestation of vines increases greatly and berries become more susceptible to diseases.
\end{abstract}

Keywords: leafroller, Epiphyas postvittana, grape, yield loss, botrytis.

\section{INTRODUCTION}

Leafrollers (Lepidoptera: Tortricidae) are one of the main pests of grapevines in New Zealand and Australia (Baker et al. 1994). There are several pest species, but the most widespread in both countries is the lightbrown apple moth (LBAM) Epiphyas postvittana (Walker). The larvae feed on leaves and new shoots of vines, but more importantly damage grape bunches directly by feeding on the flowers, berries and stalks. In addition, damaged berries are susceptible to infection by fungi such as Botrytis cinerea, which leads to further indirect losses from diseases. Leafroller larvae also spread botrytis spores through bunches, increasing both the severity of infection within a bunch and the incidence of infected bunches (Bailey et al. 1997).

LBAM have four generations per year in northern New Zealand, three generations in the southern North Island and northern South Island, and two generations further south (Wearing et al. 1991). In Hawke's Bay, trap catches of males generally increase between spring and autumn with peaks around October, January and March. Larvae are present in vineyards and orchards throughout the year, but tend to be more abundant following the emergence of each generation of adults.

In Australia the reduction in yield due to leafrollers, in a worst case situation of a high population and moist conditions, was estimated at approximately $\$ N Z 2500$ per ha (Bailey et al. 1996). The equivalent yield loss in New Zealand has not been previously measured and an economic estimate of losses due to this pest has not been attempted. Here we report on a trial that quantified the direct and indirect losses of grapes caused by artificially infesting bunches with leafroller larvae at different times during the season.

\section{METHODS}

The trial was conducted on Chardonnay grapes on a HortResearch block in Hawke's Bay. In December 1997 five evenly-sized bunches were tagged on each of 60 vines. Each vine represented one replicate and the treatments (larval infestation at different dates) were randomly assigned to each bunch. The tagged bunches were 
spaced as far apart as possible on each vine to minimise the chance of larvae moving between bunches.

Bunches were infested with LBAM larvae at monthly intervals between flowering and harvest as follows: 11 December 1997, 7 January, 2 February and 5 March 1998. On each date, two larvae were placed on each of the 60 bunches in the appropriate treatment. Control bunches were left uninfested. Second-instar caterpillars were used because their survival in the vineyard was expected to be greater than for first instars, and because their larger size made them easier to handle. The larvae came from a laboratory colony in Auckland maintained by HortResearch.

The vines received a standard fungicide programme but no insecticides during the trial. Pheromone mating disruption was used across the 0.5 ha trial block to minimise naturally occurring infestation by leafrollers, whilst having no effect on our experimental larvae. Pheromone dispensers (Isomate-LBAM, ShinEtsu Chemical Co.) for LBAM were put out in late December at a rate of $1000 /$ ha. The vines were covered by netting in early February to protect the ripening grapes from birds.

The ripe bunches were harvested on 6 April, weighed and dissected. All collapsed and diseased berries were counted and removed before the bunch was re-weighed. The damaged berries were classified as follows: collapsed due to leafroller feeding, diseased with or without sign of leafroller damage or damaged by undetermined causes. Berries that had been chewed by leafroller larvae but which were still turgid and essentially whole, were counted as being undamaged.

Analyses of variance (ANOVA) were performed on the raw data for total bunch weights and on log-transformed data for damaged berries. Differences between means were examined using Tukey's test. Birds attacked 60 bunches, which were excluded from the data analysis. Leafroller larvae failed to establish on a further 57 bunches, which were used only in the estimates of bunch weights and to compare the incidence of disease with bunches where larvae successfully established. The fresh weight of berries was estimated from a sample of undamaged bunches.

\section{RESULTS}

The mean weight of bunches at harvest did not differ between the five treatments when the equivalent fresh weight of damaged berries was included (Table 1). The greatest total losses $(\mathrm{P}<0.001)$ occurred in the December and March treatments when $12 \%$ of berries were damaged. A significant loss was also recorded in the February treatment, but losses from infestations in January did not differ from the controls (Fig. 1). We successfully established larvae on approximately $75 \%$ of bunches in December, February and March, but on only $45 \%$ in January. The average fresh weight of 1619 undamaged grapes on 12 control bunches was $1.53 \mathrm{~g}$.

TABLE 1: Mean weight (SEM) of bunches at harvest and percentage weight loss in bunches infested by leafroller larvae in different months.

\begin{tabular}{|c|c|c|c|c|c|c|c|c|}
\hline \multirow[b]{2}{*}{ Treatment } & \multirow[b]{2}{*}{$\mathrm{n}$} & \multicolumn{2}{|c|}{ Mean weight ${ }^{1}$} & \multicolumn{3}{|c|}{$\%$ weight loss by cause } & \multicolumn{2}{|r|}{ P-value ${ }^{2}$} \\
\hline & & (g) & (SEM) & Leafroller & Disease & Unknown & Total & $(\mathrm{df}=2)$ \\
\hline December & 34 & 240.0 & $(13.8)$ & 10.5 & 0.9 & 0.4 & 11.8 & $\mathrm{P}<0.001$ \\
\hline January & 20 & 237.8 & $(12.0)$ & 2.1 & 1.5 & 0.2 & 3.7 & $\mathrm{P}<0.01$ \\
\hline February & 38 & 229.5 & $(9.4)$ & 4.0 & 4.6 & 1.1 & 9.7 & $\mathrm{P}<0.001$ \\
\hline March & 42 & 241.5 & $(13.4)$ & 4.0 & 7.6 & 0.6 & 12.1 & $\mathrm{P}<0.001$ \\
\hline Control & 50 & 249.1 & $(9.5)$ & 0.6 & 0.2 & 1.2 & 1.9 & $\mathrm{P}<0.05$ \\
\hline \multicolumn{2}{|c|}{ P-value $(\mathrm{df}=4)$} & & $0.05^{3}$ & $\mathrm{P}<0.001^{4}$ & $\mathrm{P}<0.01^{4}$ & $\mathrm{P}>0.05^{4}$ & $\mathrm{P}<0.00$ & \\
\hline
\end{tabular}

${ }^{1}$ Includes the equivalent fresh weight of damaged berries.

${ }^{2} \mathrm{P}$-value for the difference between weight loss causes in the log-transformed number of berries lost to each cause.

${ }^{3} \mathrm{P}$-value for the difference between months in the untransformed bunch weight data.

${ }^{4} \mathrm{P}$-value for the difference between months in the log-transformed number of damaged berries for each cause of damage. 


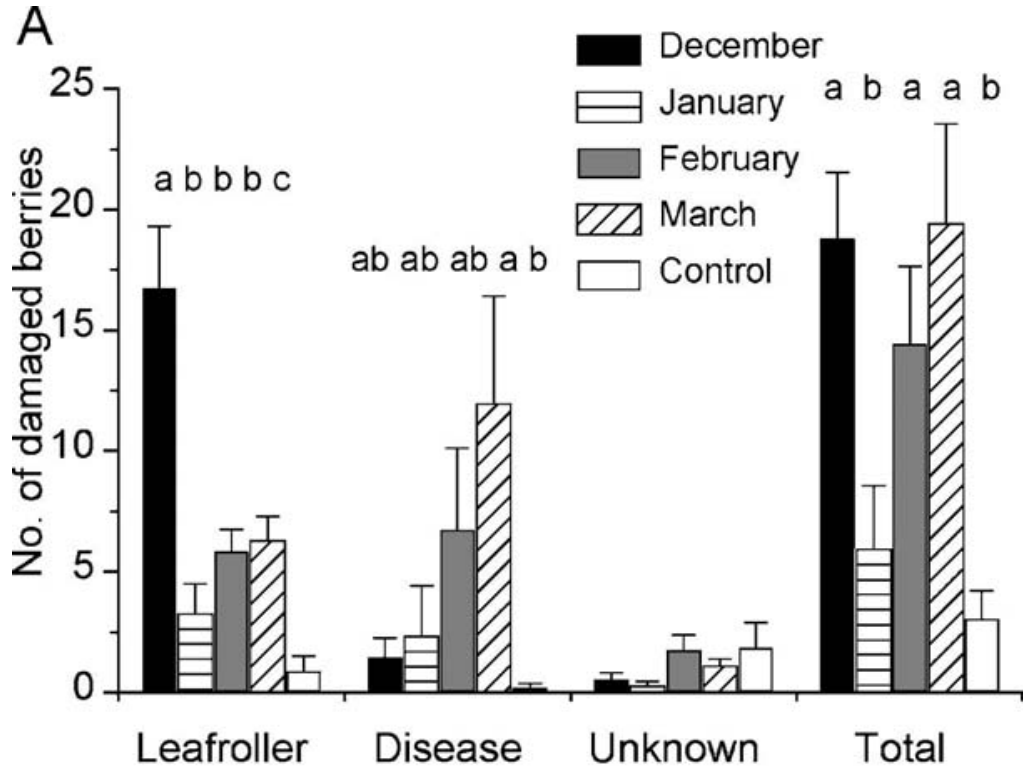

B

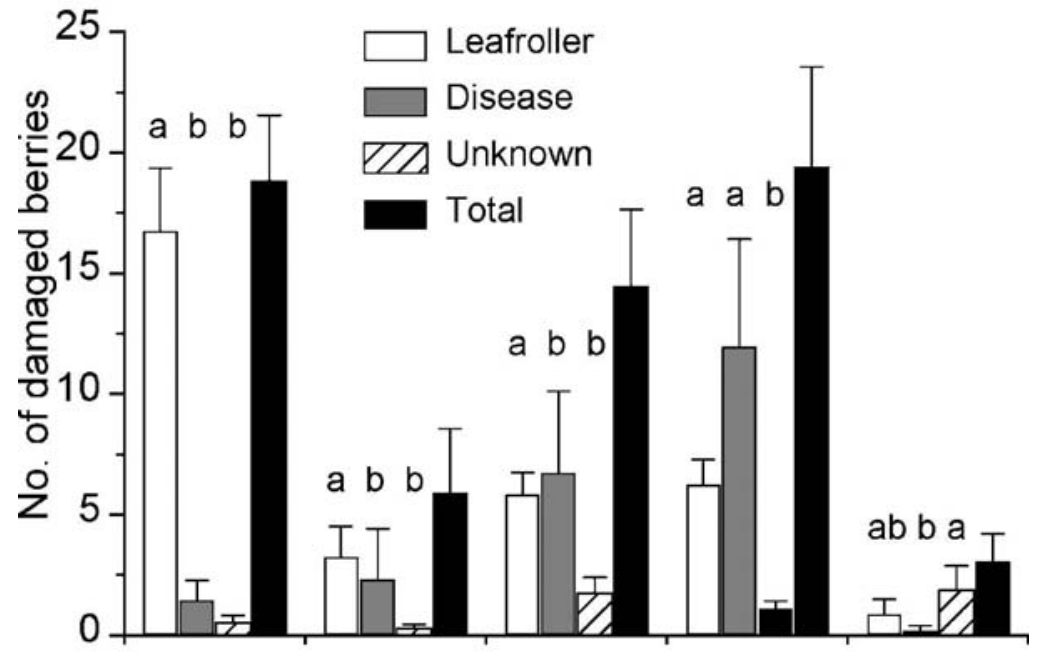

December January February March Control

FIGURE 1: Mean number (+SEM) of damaged berries per bunch. Data are grouped by (A) cause of damage and (B) month of infestation by leafroller larvae. For each group of columns, different letters above each column indicate significant differences between means (for log transformed data). 
The greatest loss of berries occurred in the December and March treatments, but for different reasons (Fig. 1, Table 1). The infestation of bunches in December caused more direct losses of berries to feeding by larvae than in other months, although all four treatments had greater losses than the controls. In contrast, the incidence of disease gradually increased with successive infestations, but only in March was the weight loss significantly greater than in control bunches, because the number of diseased berries per bunch was highly variable. The low level of disease on control bunches showed that virtually all the disease in the other treatments was due to damage caused by caterpillars. Approximately $15 \%$ of the control bunches were damaged by wild leafrollers, but the direct damage amounted to less than $1 \%$ of berries in total. In addition to damage causing berries to collapse, larvae had chewed a further $1-5 \%$ of berries per treatment that had not collapsed or become diseased.

The association between leafrollers and the incidence of disease is shown in Fig. 2. Between 10-15\% of bunches that were either successfully infested in December and January, naturally infested controls or those without leafrollers, contained some diseased berries. This indicates that leafroller infestations up to January did not increase disease levels much above the background level of infection. In contrast, infesting bunches in February and March, when bunches were most susceptible to disease, increased the proportion of bunches with botrytis to $32 \%$ and $38 \%$ respectively. There was a trend $(\mathrm{P}>0.05)$ for a higher number of diseased berries per infested bunch with later inoculations of larvae, but sample sizes were small.

The weather during the trial was exceptionally dry, with only $73 \mathrm{~mm}$ of rain at the trial site between 1 December 1997 and 31 March 1998. This was a third of the average rainfall of $213 \mathrm{~mm}$ for the same period between 1983 and 2000 (HortResearch weather records).

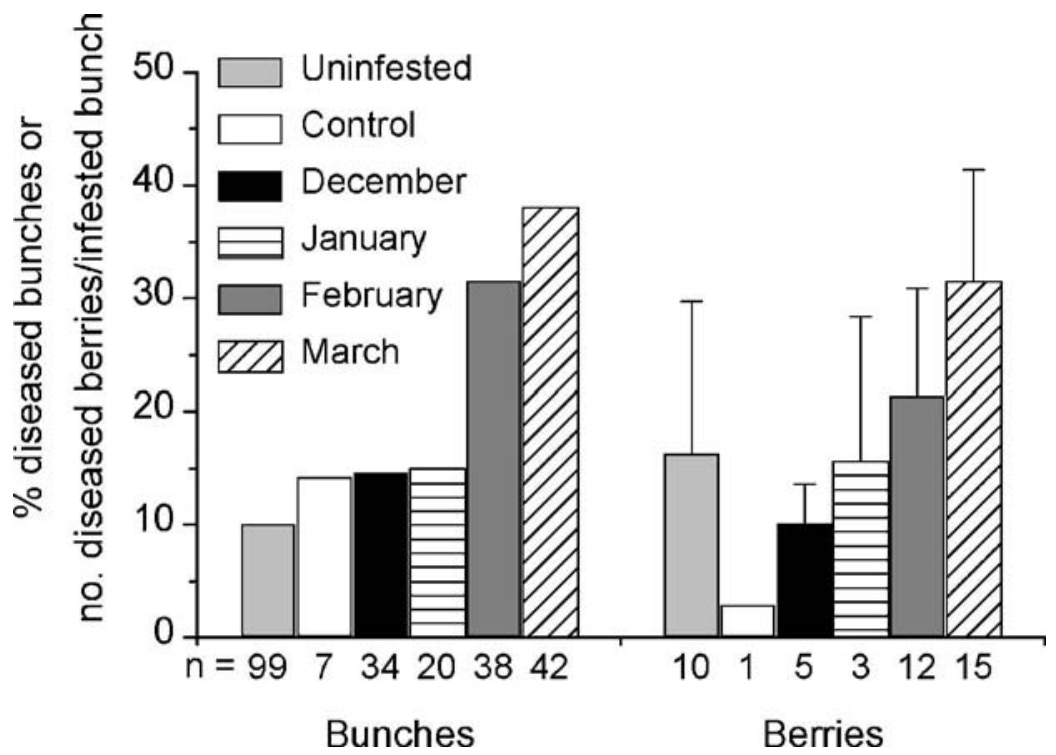

FIGURE 2: The proportion of bunches in each treatment successfully infested with leafrollers that contained diseased berries at harvest, and the mean number (+SEM) of diseased berries/infested bunch. A comparison is also made with naturally infested controls and uninfested bunches. $\mathbf{n}=$ sample size. 


\section{DISCUSSION}

The timing of leafroller infestations had a major influence on the type of damage to grape bunches. Early infestations caused the greatest direct losses because with only small berries present larvae fed mainly on stalks, which killed whole groups of berries. As the season progressed, larvae fed more on the berries themselves and damage became confined to fewer berries. Disease was an important factor later in the season because grapes become more vulnerable to diseases, particularly from veraison (berry ripening) onwards. Veraison occurs about late January in Chardonnay, so the February and March infestations of larvae coincided with the berries being highly vulnerable to botrytis. By contrast, larvae feeding on bunches in December completed their development before veraison, which allowed time for any damage to heal or wither thus eliminating potential sites for disease infection.

Monitoring of leafroller populations in Hawke's Bay vineyards during the past three years indicates that it is the second generation in mid-summer and early autumn that causes the majority of damage (P. Lo, unpubl. data). The infestation of bunches is generally less than $0.5 \%$ before January, whereas by March up to $29 \%$ has been recorded although less than 5\% is more typical. From these figures and data in Table 1 we can estimate yield losses attributable directly and indirectly to a late season infestation of leafrollers. Assuming that the reduction in yield is $12 \%$ per infested bunch, infestations of $5 \%$ and $30 \%$ of bunches are equivalent to weight losses of $0.6 \%$ and $3.6 \%$ respectively. In Hawke's Bay, grape production currently averages $8.3 \mathrm{t} / \mathrm{ha}$ with a mean price of $\$ 1200 / \mathrm{t}$ (Anon. 1999). At these levels, the estimated yield reductions equate to financial losses of $\$ 60-\$ 360 / \mathrm{ha}$.

Since the impact of leafrollers on grapes is greatest near harvest, action thresholds will depend on the interaction between their abundance and the risk of botrytis infection. Thresholds are likely to differ between wet and dry years, because rainfall is a key variable that affects the incidence of several diseases, particularly botrytis, and possibly also the abundance of leafrollers. Another factor to consider when setting thresholds is the grape variety, since juice prices and tonnages vary by 3-4 fold (Anon. 1999). Insecticides cost approximately $\$ 30-45 /$ ha (excluding application costs), so our results indicate that in a dry year it is not economic to control leafrollers when infestations are less than $5 \%$ of bunches at harvest.

In Australia, both the spring and summer generations of leafroller damage grapes (Buchanan 1977; Bailey et al. 1997). However, in hotter districts the summer generation is smaller than the spring one and the majority of damage occurs during flowering. This is in contrast to the situation in New Zealand. Australian studies show that leafrollers can potentially cause much more damage than we recorded. However, Bailey et al. (1996) did not state how they calculated their figure of $\$ 2500 /$ ha, so it may not be directly comparable with our estimate of \$60-\$360/ha. Differences in leafroller abundance and weather conditions are the most likely explanations for the large variation in the cost of damage. There were unusually dry conditions during our trial and consequently botrytis levels were very low. We expect that the incidence of botrytis due to leafroller damage would be much greater in wetter years.

In conclusion, this research concurs with Australian studies (Buchanan 1977) that the direct damage from feeding by leafroller larvae is minimal compared with the indirect losses by making bunches more vulnerable to disease. Our estimated yield loss due to leafrollers of $12 \%$ per infested bunch is likely to be a minimum figure owing to the dry weather during the trial. We should be cautious about extrapolating the losses estimated from this study to other varieties and other years because several factors will affect actual losses on vineyards. For example, different grape varieties have different susceptibilities to diseases (Nicholas et al. 1994), while leafrollers prefer some varieties to others (Baker et al. 1994). Further research on the impact of leafrollers in wet conditions is necessary before spray thresholds can be developed.

\section{ACKNOWLEDGEMENTS}

This research was funded by Winegrowers of New Zealand and the New Zealand Foundation for Research, Science and Technology. We thank Peter Wood for 
management of the trial site, and John Charles, Stephen Bradley and David Steven for their comments on the manuscript.

\section{REFERENCES}

Anon., 1999. Wine and Grape Industry Statistical Annual 1999. Winegrowers of New Zealand, Auckland. 48 pp.

Bailey, P., Baker, G. and Caon, G., 1996. Field efficacy and persistence of Bacillus thuringiensis var. kurstaki against Epiphyas postvittana (Walker) (Lepidoptera: Tortricidae) in relation to larval behaviour on grapevine leaves. Aust. J. Ent. 35: 297-302.

Bailey, P.T., Ferguson, K.L., McMahon, R. and Wicks, T.J., 1997. Transmission of Botrytis cinerea by lightbrown apple moth larvae on grapes. Aust. J. Grape and Wine Res. 3: 90-94.

Baker, G.J., Bailey, P.T. and Charles, J.G., 1994. Leaf and fruit pests: Lightbrown apple moth. Pp 47-50 In: Diseases and Pests. P.R. Nicholas, P.A. Magarey and M.F. Wachtel (Eds). Grape Production Series, no. 1. Winetitles, Australia.

Buchanan, G.A., 1977. The seasonal abundance and control of lightbrown apple moth, Epiphyas postvittana (Walker) (Lepidoptera: Tortricidae), on grapevines in Victoria. Aust. J. Agric. Res. 28: 125-132.

Nicholas, P.R., Magarey, P.A. and Wachtel, M.F. (Eds) 1994. Diseases and Pests. Grape Production Series, no. 1. Winetitles, Australia.

Wearing, C.H., Thomas, W.P., Dugdale, J.S. and Danthanarayana, W., 1991. Tortricid pests of pome and stone fruits, Australian and New Zealand species. Pp 453-472 In: Tortricid Pests: Their Biology, Natural Enemies and Control. World Crop Pests, volume 5. L.P.S. van der Geest and H.H Evenhuis (Eds). Elsevier, Amsterdam. 